\title{
Abdelmoez Hyaluronic Acid Dermal Filler Scoring System
}

\author{
Ahmed Abdelmoez Alsayed \\ Al-Hokail, Khobar, KSA \\ Email: az971986@gmail.com
}

How to cite this paper: Alsayed, A.A. (2019) Abdelmoez Hyaluronic Acid Dermal Filler Scoring System. Journal of Cosmetics, Dermatological Sciences and Applications, 9, 329-335.

https://doi.org/10.4236/jcdsa.2019.94030

Received: November 8, 2019

Accepted: December 6, 2019

Published: December 9, 2019

Copyright $\odot 2019$ by author(s) and Scientific Research Publishing Inc. This work is licensed under the Creative Commons Attribution International License (CC BY 4.0).

http://creativecommons.org/licenses/by/4.0/

\section{c) (i) Open Access}

\begin{abstract}
Introduction: Dermal fillers industry is ever-expanding. Tens, if not hundreds, of brands are available to purchase legally or illegally. I have attempted in this paper to develop a scoring system for Hyaluronic acid dermal fillers that makes an injector's verdict objective, fair and unbiased, and injection experience safer. Theoretically speaking, the worst filler will have, at least, -12 score and the best will have a score of 34 points. Some scoring points do not exist in any filler, suggesting hints to improve all brands. Objectives: To build a Hyaluronic acid dermal filler scoring system that deals with what the injector can easily read, see or experience on their own without using sophisticated technologies or the need to understand or estimate the physics or the chemistry behind the filler. Using a scoring system that depends more on objective than subjective findings will be easy and unbiased to apply, more practical. The scoring system structure should be holistic rather than being only results centered and more focused on safety.
\end{abstract}

\section{Keywords}

Hyaluronic Acid, Dermal, Filler, Scoring, System

\section{Introduction}

Speaking only about the major dermal filler manufacturers, the global dermal fillers market size was valued at USD 3.47 Billion in 2018 and is projected to reach USD 6.3 Billion by 2026. Hyaluronic acid takes the biggest share of the dermal filler market that is estimated by (77.2\%) [1].

There are tens, maybe hundreds, of other less known Hyaluronic acid dermal filler brands worldwide produced by national, local or wholesale manufacturers, and sold through distributors, third parties or online to find their way sometimes to customers in countries even with strict pharmaceutical regulations. 
When injectors are offered Hyaluronic acid dermal filler brands that they have never heard of to try, here comes the need for a scoring system.

United States of America Food \& Drug Administration (FDA) approval and major manufacturers' reputation definitely matter. However, Hyaluronic acid dermal fillers are injected all over the world in other countries that have their own regulating authorities. FDA is an American federal agency that is responsible for protecting and promoting public health [2]. However, as any other authority, FDA still faces criticism [3]-[8]. Growing manufacturers may be unfairly judged despite having a considerably good Hyaluronic acid filler [6].

\section{Methods}

While designing a Hyaluronic acid dermal filler scoring system (see Table 1), I considered the following points:

1) The scoring system deals with what the injector can easily read, see or experience on their own without using sophisticated technologies e.g. 3D cameras and without the need to understand or estimate the physics or the chemistry behind the Hyaluronic acid dermal filler e.g. innovations in crosslinking or superiority in physical properties. Approvals by official bodies and scientific literature can fill the gap and are considered as scoring points.

2) The scoring system depends more on objective than subjective findings, meaning that several aspects can be accurately judged by absolute findings, unlike other scoring scales that depend mainly on subjective criteria (Table 2) by assessing the wrinkles severity or variation of injected area volume over time and sometimes demand sophisticated technologies, injection associated pain and discomfort scoring or patient satisfaction scoring. The thing that makes my scoring system more practical, easier to be applied, more focused on safety, holistic rather than being only results centered and accordingly unique in literature.

3) The scoring system does not only depend on judging the filler substance, but also comprises other components of the package e.g. the syringe, the needle, the manufacturer, the evidence, etc.

4) The scoring system does not consider individual variations regarding skills, techniques or personal injector preferences.

5) The scoring system has minus grades for mentioned, or even unmentioned, absolutely contraindicated findings that may threaten the patient safety if they were just reported even by another injector or in a literature source at least once. Other unfavorable, yet not dangerous, findings should be personally experienced more than twice to be considered in the grading process.

6) The scoring system gives zero grade to positive yet basic characteristics of the product. Such characteristics are critical for patient safety.

7) Official prices were not considered as a factor in the scoring process.

8) Theoretically speaking, the worst filler will have, at least, -12 score and the best will have a score of 34 points. 
Table 1. Abdelmoez Hyaluronic acid dermal filler scoring system.

\begin{tabular}{|c|c|c|}
\hline \multicolumn{3}{|c|}{ The Score } \\
\hline 1 & $\begin{array}{l}\text { Manufacturer } \\
\text { (Check the reputation of the manufacturer and } \\
\text { if it is a real, physically existing identity } \\
\text { with real address and real country of origin) }\end{array}$ & $\begin{array}{l}0 \text { : Unreal } \\
\text { 1: Real }\end{array}$ \\
\hline 2 & $\begin{array}{l}\text { Approval } \\
\text { (Check if the brand is approved by different approval entities. } \\
\text { Pending or expired approvals don not count) }\end{array}$ & $\begin{array}{l}\text { 0: Non-approved } \\
\text { 1: CE mark, else [19] } \\
\text { 2: Nationally } \\
\text { approved [20] } \\
\text { 3: US FDA } \\
\text { approved [21] }\end{array}$ \\
\hline 3 & $\begin{array}{c}\text { Evidence based quality } \\
\text { (Check if there is, at least one, scientific literature proving the } \\
\text { brand quality or uniqueness of technology. Must be } \\
\text { published in a reputable journal without conflict of interest) }\end{array}$ & $\begin{array}{l}\text { 0: Non-approved } \\
\text { 2: Approved by } \\
\text { technology name } \\
\text { 2: Approved by brand } \\
\text { name } \\
\text { 4: Approved by both }\end{array}$ \\
\hline \multirow{4}{*}{4} & \multirow[t]{2}{*}{\begin{tabular}{l}
\multicolumn{1}{c}{ Boxing } \\
- Unique design* \\
- Clear differentiation of varieties \\
like using different colors, \\
mentioning variety name clearly, \\
concentrations and cross-linking \\
- Proof of authenticity or online \\
anti-faking element (through \\
an application or a website)
\end{tabular}} & $\begin{array}{l}\text { Point for each } \\
(0-3)\end{array}$ \\
\hline & & $\begin{array}{l}-1 \text { : Not sealed } \\
0: \text { Sealed } \\
\text { 1: General product } \\
\text { details printed } \\
\text { on the seal } \\
\text { 2: General and unique } \\
\text { product details } \\
\text { printed on the seal }\end{array}$ \\
\hline & $\begin{array}{l}\text { Pamphlet included: } \\
\text { Multilingual (including the country } \\
\text { of the distribution, Technical } \\
\text { details included) }\end{array}$ & $\begin{array}{l}-1: \text { No } \\
\text { Fairly detailed: } 0 \\
\text { Perfectly detailed: } 1\end{array}$ \\
\hline & $\begin{array}{l}\text { Uniqueness of sticker } \\
\text { - Unique Serial number on the sticker } \\
\text { - Online usable for authenticity check } \\
\text { - Serial number is barcoded } \\
\circ \text { Oneral stickers (at least } 4) \text { for treatment plan. } \\
\circ \quad \text { One for consent. } \\
\circ \text { One for charging sheet. } \\
\circ \quad \text { One for nursing procedure logbook }\end{array}$ & $\begin{array}{l}\text { Point for each } \\
(0-4)\end{array}$ \\
\hline 5 & \begin{tabular}{l}
\multicolumn{1}{c}{ Needles } \\
- Flexibility \\
- Caliber-concentration matching \\
- Sharpness after multiple entries \\
- Smooth movement on extraction ${ }^{* *}$ \\
- Cannula is supplied
\end{tabular} & $\begin{array}{l}\text { Point for each } \\
(0-5)\end{array}$ \\
\hline
\end{tabular}


6

Syringe Ergonometrics/Design
Uniqueness of design*

-1 : Uniform

0 : Unique

- Hand friendly grip

- $360^{\circ}$ rotatable barrel

flange***

- $360^{\circ}$ rotatable plunger flange ${ }^{* * *}$

- $360^{\circ}$ rotatable luer lock system ${ }^{* * *}$

- $360^{\circ}$ grading visibility ${ }^{* *}$

- Aspiration friendly design

Plunger tip dislocation from the rubber seal during aspiration incident reported

Luer lock system dislocation accidents

Grading marks and clear differentiation of varieties like concentrations and grades of cross-linking

Each variety has a unique syringe color/hue

Ease of injection

Pliability vs Stability

Being inert

(Reactions or granuloma incidences)
Point for each

$(0-6)$

-1 : Yes, for each incident

0 : No

-1 : Reported, for each incident 0 : Not reported

-1 : Lost, for each incident

0 : Sticker on syringe

1: Printed on syringe

-1 : No

0 : Yes

-1 : Heterogenous resistances experienced during injection using the same syringe 0: Homogenous but too easy or too hard considering concentration and cross-linking

1: Reasonable

-1 : Major migration incident reported, for each incident 0: Still Pliable after one week 0 : Integrated with tissues before one week 1: Pliable till the first weekends then it starts to integrate

-1 : Reported, for each incident 0 : Not reported 


\section{Continued}

Longevity

(Depending on self, more than 2 case reports)

Actual Volume $=$ Graded Volume
-1 : Mostly disappears before half of the expected span ends -1 : Mostly persists after double of the expected span ends, for each incident 1: Mostly disappears by the end of the expected span, for each incident 0 : Between above -1 and 1 scores

0 : No

1: Yes

-1 : No 0 : Yes

$-1:$ Yes

0 : No specification/incident that can absolutely endanger the patient safety

Total Score

*: Unique design can be considered as an evidence that the product is not made by a wholesale manufacturer; ${ }^{* *}$ : Smooth needle extraction without getting caught up/jammed with the skin, especially lips, during retrograde injection ensures equal thickness along the filler injected thread; ${ }^{* *}$ : The four marked points will fulfill the perfect injection grip elements: comfortable fingers positioning, visible grading and correct direction of the needle bevel on both sides of patient's face.

Table 2. Examples of popular subjective scoring systems that assess the wrinkles severity or variation of injected area volume over time.

Wrinkle Severity Rating Scale (WSRS) [9]

Global Aesthetic Improvement Scale (GAIS) [10]

Medicis Lip Fullness Scale [11]

The Initial Allergan Lip Fullness Scale (iLFS) [12]

The Revised Allergan Lip Fullness Scale (LFS) [12]

Glabellar Severity Score [13]

Mid-Face Volume Deficit Scale (MFVDS) [14]

Lemperle Rating Scale (LRS) [15]

Merz Hand Grading Scale [16]

5-Point Wrinkle Assessment Scale (WAS) [17]

Modified Fitzpatrick Wrinkle Scale (MFWS) [18]

9) Majority of the points focus on patient safety, quality of injection experienced and results seen by the injector.

10) Some scoring points do not exist in any filler, suggesting hints to improve all products. 
11) The importance of such a score is more prominent in countries with permissive regulations regarding filler brands allowed to use.

\section{Discussion}

My scoring system essentially depends on my experience. Feedback is required from readers side to check how practical the scoring system is and if it significantly relates to the procedure results and customer satisfaction. Next target is other dermal fillers and neuromodulators.

\section{Conclusion}

In the era of countless dermal filler brands and ever-growing market, a practical and unbiased scoring system is needed to emphasize product quality and patient safety.

\section{Conflicts of Interest}

The author declares no conflicts of interest regarding the publication of this paper.

\section{References}

[1] (2019) Dermal Fillers Market Size, Share and Industry Analysis by Product (Biodegradable, Non-Biodegradable), by Ingredient (Hyaluronic Acid, Calcium Hydroxylapatite Poly-L-lactic Acid, PMMA (Poly (methyl methacrylate)), Fat Fillers), by Application (Scar Treatment, Wrinkle Correction Treatment, Lip Enhancement. Restoration of Volume/Fullness) and Regional Forecast 2019-2026.

https://www.fortunebusinessinsights.com/industry-reports/dermal-fillers-market-1 $\underline{00939}$

[2] U.S. Food and Drug Administration (2008) What We Do. https://www.fda.gov/about-fda/what-we-do

[3] Henderson, D. (2006) Panel: FDA Needs More Power, Funds. The Boston Globe.

[4] Committee on the Assessment of the US Drug Safety System (2006) The Future of Drug Safety: Promoting and Protecting the Health of the Public. National Academy of Medicine, Washington DC.

[5] Mundy, A. and Favole, J.A. (2009) FDA Scientists Ask Obama to Restructure Drug Agency. The Wall Street Journal.

[6] Williams, R., Scharff, R. and Bieler, D. (2010) Food Safety in the 21st Century. Mercatus on Policy. 71.

[7] Jonathan (2016) The Lack of EpiPen Competitors Is the FDA's Fault-Jonathan Newman.

[8] Zuckerman, D.M., Brown, P. and Nissen, S.E. (2011) Medical Device Recalls and the FDA Approval Process. Archives of Internal Medicine, 171, 1006-1011. https://doi.org/10.1001/archinternmed.2011.30

[9] Narins, R.S., Brandt, F., Leyden, J., Lorenc, Z.P., Rubin, M., et al. (2003) A Randomized, Double-Blind, Multicenter Comparison of the Efficacy and Tolerability of Restylane versus Zyplast for the Correction of Nasolabial Folds. Dermatologic Surgery, 29, 588-595. https://doi.org/10.1046/j.1524-4725.2003.29150.x

[10] Day, D.J., Littler, C.M., Swift, R.W. and Gottlieb, S. (2004) The Wrinkle Severity 
Rating Scale: A Validation Study. American Journal of Clinical Dermatology, 5, 49-52. https://doi.org/10.2165/00128071-200405010-00007

[11] Kane, M.A.C., Lorenc, Z.P., Lin, X.M. and Smith, S.R. (2012) Validation of a Lip Fullness Scale for Assessment of Lip Augmentation. Plastic and Reconstructive Surgery, 129, 822e-828e. https://doi.org/10.1097/PRS.0b013e31824a2df0

[12] Werschler, W.P., Fagien, S., Thomas, J., Paradkar-Mitragotri, D., Rotunda, A. and Beddingfield III, F.C. (2015) Development and Validation of a Photographic Scale for Assessment of Lip Fullness. Aesthetic Surgery Journal, 35, 294-307. https://doi.org/10.1093/asj/sju025

[13] Honeck, P., Weiss, C., Sterry, W. and Rzany, B. (2003) Reproducibility of a Four-Point Clinical Severity Score for Glabellar Frown Lines. The British Journal of Dermatology, 149, 306-310. https://doi.org/10.1046/j.1365-2133.2003.05436.x

[14] Jones, D. and Murphy, D. (2013) Volumizing Hyaluronic Acid Filler for Midface Volume Deficit: 2-Year Results from a Pivotal Single-Blind Randomized Controlled Study. Dermatologic Surgery, 39, 1602-1612. https://doi.org/10.1111/dsu.12343

[15] Lemperle, G. (2015) A Classification of Facial Wrinkles. UC, San Diego. https://escholarship.org/uc/item/5367f9z0

[16] Cohen, J.L., Carruthers, A., Jones, D.H., Narurkar, V.A., Wong, M., Cheskin, L.N., Trout, J.R. and Howell, D.J. (2015) A Randomized, Blinded Study to Validate the Merz Hand Grading Scale for Use in Live Assessments. Dermatologic Surgery, 41, S384-S388. https://doi.org/10.1097/DSS.0000000000000553

[17] Lemperle, G., Holmes, R., Cohen, S. and Lemperle, S. (2001) A Classification of Facial Wrinkles. Plastic and Reconstructive Surgery, 108, 1735-1750. https://doi.org/10.1097/00006534-200111000-00050

[18] Shoshani, D., Markovitz, E., Monstrey, S.J. and Narins, D.J. (2008) The Modified Fitzpatrick Wrinkle Scale: A Clinical Validated Measurement Tool for Nasolabial Wrinkle Severity Assessment. Dermatologic Surgery, 34, S85-S91. https://doi.org/10.1111/j.1524-4725.2008.34248.x

[19] European Commission. Search the Database. https://ec.europa.eu/growth/tools-databases/tris/en/search

[20] World Health Organization. List of Globally Identified Websites of Medicines Regulatory Authorities.

https://www.who.int/medicines/areas/quality_safety/regulation_legislation/list_mra _websites_nov2012.pdf

[21] United States of America Food \& Drug Administration, Homepage. https://www.fda.gov 